\title{
Busca De Variáveis Modificáveis Dos Cuidadores De Idosos Com Demência Que Permitam Melhorar 0 Cuidado Prestado Pelos Cuidadores A Esses Pacientes
}

\author{
Dalpai, D.; Reis, R.C.; Camozzato, A.;
}

Apresentador: Débora Dal Pai

\section{Resumo}

Introdução: As estratégias de manejo dos cuidadores em relação aos sintomas apresentados por pacientes com demência institucionalizados merecem investigação. O objetivo deste estudo foi avaliar a correlação de variáveis clínicas e demográficas dos cuidadores com diferentes formas de manejo. Método: Um estudo transversal foi usado. A amostra nele incluída é composta de 45 cuidadores profissionais, provenientes de duas instituições de longa permanência para idosos de Porto Alegre, Brasil. Idade, anos de estudo, questionário socioeconômico, anos de trabalho como cuidador, sobrecarga, sintomas ansiosos e depressivos dos cuidadores, bem como, as estratégias de gerenciamento da demência foram avaliadas para todos os participantes do estudo. As escalas utilizadas foram: questionário de classificação econômica no Brasil da ABEP, Inventário de Sobrecarga de Zarit (ZBI), Inventário de Depressão de Beck (BDI), Inventário de Ansiedade de Beck (BAI), Escala de Estratégias de Gerenciamento da Demência (EEGD). A análise estatística realizada foi uma correlação de cada tipo de estratégia de gerenciamento da demência (criticismo, encorajamento e manejo ativo) com todos os dados demográficos e clínicos dos cuidadores por meio do teste de correlação de Pearson. O SPSS v17 foi usado para a análise. $\mathrm{P}<0.01$ foi considerado como estatisticamente significativo. Resultados: A estratégia de gerenciamento da demência mais usada pelos cuidadores foi o manejo ativo. $\mathrm{O}$ item criticismo da EEGD apresentou uma correlação significativa e moderada com o escore do ZBI ( $\mathrm{r}$ $=0.572, \mathrm{p}<0.001)$. Outras correlações não foram observadas. Conclusões: Criticismo é uma forma autoritária de manejo da demência e o ZBI avalia a sobrecarga do cuidador, assim, quanto maior a sobrecarga, maior é o uso do criticismo. Este é um estudo exploratório, com uma amostra pequena. Apesar dessas limitações, a relevância deste estudo consiste na investigação de um importante aspecto que influencia o tratamento e a qualidade de vida dos pacientes com demência: a forma do cuidado que é prestado. Portanto, melhorar o cuidado parece ser uma forma possível de melhorar o curso natural da demência.

\section{Referência:}

Dalpai, D.; Reis, R.C.; Camozzato, A.;. Busca De Variáveis Modificáveis Dos Cuidadores De Idosos Com Demência Que Permitam Melhorar O Cuidado Prestado Pelos Cuidadores A Esses Pacientes. In: Il Congresso Brasileiro de Medicina Hospitalar - II CBMH [= Blucher Medical Proceedings, vol.1, num.5] São Paulo: Editora Blucher, 2014. p.25

DOI 10.5151/medpro-II-cbmh-017 